\title{
Regarding One Estimation of the Technical Condition of the Selective Headers
}

\author{
Kovalev $^{1}$ Vladimir A., Khoreshok ${ }^{1,2}$ Alexey A., Gerike ${ }^{1,2}$ Boris L., Meshkov ${ }^{1,3}$ Anatoliy A. \\ ${ }^{1}$ T. F. Gorbachev Kuzbass State Technical University \\ ${ }^{2}$ Institute of Coal of the SB RAS (the Siberian Branch of the Russian Academy of Science), Kemerovo \\ ${ }^{3}$ SUEK-Kuzbass \\ haa.omit@kuzstu.ru.
}

\begin{abstract}
The paper presents an issue of estimation of the technical condition of the selective headers applying mathematical model of alteration of the actual condition of an object of diagnostics. The paper shows that a complex method is more relevant to the selective headers; the method is based on emission-and-spectrum analysis of lubricant oil for cutting gear, and analysis of mechanical vibration in cutting drive. As an example of degradation of the cutting gear in a header SM-130K as per alteration of mechanical impurities content in lubricant oil and vibration intensity on the cutting gear mounting group has been reviewed.

It is shown that the developed forecast model, based on statistical analysis of the results of the lubricant oil and parameters of mechanical vibrations, allows with $95 \%$ confidence probability to predict a moment of the cutting gear breakdown and schedule a timely maintenance.
\end{abstract}

Keywords - selective header, technical condition, life-time, prognosis model, emission-and-spectrum analysis of lubricant oil, vibration-based diagnostics

\section{INTRODUCTION}

There is a requirement for evaluation of remaining life at planning of the equipment technical inspection cycle in order to ensure operational safety and extend service life-time for mining equipment when the exhaustion of the specified lifetime has place. [1-3].

As a rule, evaluation of the remaining life uses a simplified approach, not considering random nature of degradation of parameters of the technical condition of equipment and not assessing reliability of the forecast.

More accurate methods of prediction of the remaining life for safe operation are based on the determination of regularities of development of defects and damages, statistical data processing, extrapolation of trends to the maximum permissible values, and probabilistic assessment of values of the indicators.

Methods of assessment and prediction of equipment lifetime is divided into four groups: deterministic, expert, physical and statistical, and factual data [4].

The deterministic methods provide analytical dependence linking the time before failure of an object with the characteristics of operational loads and parameters of physical-chemical processes. However, these methods do not take into account random nature of loads and changes in materials.

The expert methods require presence of the qualified professional experts of various profiles conducting expertise.

The physical and statistical methods consider influence of various physical and chemical factors contributing to the development of degradation processes as well as actual operational loads at evaluating operational life-time of equipment.

Out of the known factual data methods based on the data about the object of prediction and its past development in order to forecast the remaining life of equipment they mainly use two methods:

- statistics method based on the statistical processing of data regarding the failures and life-time of analogues;

- extrapolation method based on the trend analysis of parameters of the technical condition of the diagnosed equipment.

\section{METHOD.}

Mathematical model of evaluation of the actual condition of an object is based on the following terms and assumptions $[5,6]$.

Currently available set of technical parameters (forming a space of technical parameters) of an object depends on:

- initial condition of an object;

- operation mode of an object;

- history of operation conditions;

- mode.

In this case the operating conditions should be understood as workloads, systematic and random factors of external influences, etc.

The mode of operation of the object provides the unfolding in time of the set of technical and technological processes, each of which is characterized by a set of operating parameters.

Change in technical parameters of the object can be described by the equation of condition, which can be done by 
evolutionary or differential equation, deterministic or stochastic, depending on the values included into the right part

$$
x(t)=F\left\{x\left(t_{0}\right), u_{\left[t_{0}, t\right]}, K\right\} .
$$

Set of technical parameters of the object can be judged by the results of direct or indirect measurements of diagnostic performance, the combination of which depends on the actual condition of the object at the time of measurement and the conditions under which they were made. The measurement equation has stochastic nature due to its very nature

$$
y(t)=G[x(t), u(t)] .
$$

The estimate of the true values of the technical parameters of the object is made according to the obtained set of measurements. This process can be described by deterministic equation estimates

$$
\widehat{x}(t)=H y(t) .
$$

Then the actual condition of the object (state vector) is evaluated, which is judged by set of estimates of the true values of the technical parameters of the object obtained under the given conditions $[7,8]$

$$
\Phi(t)=\Psi[\widehat{x}(t), u(t)]
$$

In this case, the remaining life of the object is calculated by a mathematical model and is defined by the combined evaluations of the technical parameters of the object, equation of condition, operating conditions, actual condition of the object and set of the limit technical parameters

$$
R(t)=W[t, \hat{x}(t), u(t), \bar{x}, \Phi(t)] .
$$

The equation (1)...(5) use the legend as follows:

$x(t)$ - vector of technical (diagnostic) parameters; of time;

$u(t)$ - operating conditions of the object at current moment

$$
u_{\left[t_{0}, t\right]} \text { - operating conditions of the object in time interval }
$$
$\left[t_{0}, t\right]$

$K$ - vector characterizing mode of operation of the object;

$y(t)$ - results of diagnostic measurements;

$\hat{x}(t)$

$\Phi(t)$ - evaluation of actual condition of the object at moment of time $t$;

$R(t)$ - estimation of the remaining life at moment of time $t$;

$\bar{x}$ - limit values of the technical parameters.

Thus t0 in equation (1) should be taken as a moment of commencement of operation of the object, and when the remaining life is evaluated as a moment of assessment of technical condition of the object.

As the results of diagnostic measurements are chance variables, then the described model cannot be considered fully as deterministic, so it is necessary to use statistical laws of measurements and their stochastic correlations with measures of the actual condition of the object under diagnostic. In fact, assessment of the true values of the technical parameters in accordance with the equation (3) is the problem of recognition of the condition under which the diagnostic object is, so the probabilistic approach could solve the problem.

Used for diagnosis data is generally 'noisy', so any of the measured parameters can be expressed as the sum of deterministic and chance component. For a reliable forecast of the remaining life of complex systems it is required to build and implement the algorithm of complete separation of the deterministic and chance components.

With not considerable number of observations $(N \leq 50)$ the correlation with confidence level of $p_{0}$ is considered as substantial (significant), if the condition $t_{p}>t_{\alpha}$ is met

$$
t_{p}=r \sqrt{\frac{N-2}{1-r^{2}}},
$$

where $t_{p}$ - computed value of Student's coefficient, a $t_{\alpha}-$ table value of Students' coefficient for level of significant $\alpha=(1-$ $p_{0}$ ) and number of degrees if freedom $k=N-2$.

The obtained values of the linear regression coefficients are statistical estimates and characterized by their confidence interval, the boundaries of which in practice are defined as the confidence interval $\Delta$ and forecast interval $\delta$ [8]

$$
\begin{gathered}
\Delta=\sqrt{\frac{\sum_{1}^{N}\left(\bar{K}-K_{i}\right)^{2}}{N-2} \times\left[1+\frac{1}{N}+\frac{\left(t_{i}-\bar{t}\right)^{2}}{\sum_{1}^{N} t_{i}^{2}-N \bar{t}^{2}}\right]} \\
\delta=\sqrt{\frac{\sum_{1}^{N}\left(\bar{K}-K_{i}\right)^{2}}{N-2} \times\left[\frac{1}{N}+\frac{\left(t_{i}-\bar{t}\right)^{2}}{\sum_{1}^{N} t_{i}^{2}-N \bar{t}^{2}}\right]} .
\end{gathered}
$$

In general case, the task of prediction of the remaining life of the diagnosed system as per to the set of values of the diagnostic parameter obtained based on periodic monitoring data is narrowed down to extrapolation of the found trend and determination of time of its intersections with the lines, defining the threshold condition.

\section{MAIN PART}

As forecast parameters, this paper proposes to apply an integrated approach to the assessment of the remaining life based on the analysis of mechanical impurities in lubricant oil and the magnitude of mechanical vibrations of the gearbox of the cutting part [9].

To analyze the taken samples of oil from the gearbox of the cutting part of the header SM-130K a multiband photometric system MFS-7 is used, which is based on spectral analysis of the combustion products and determines content of the following: 


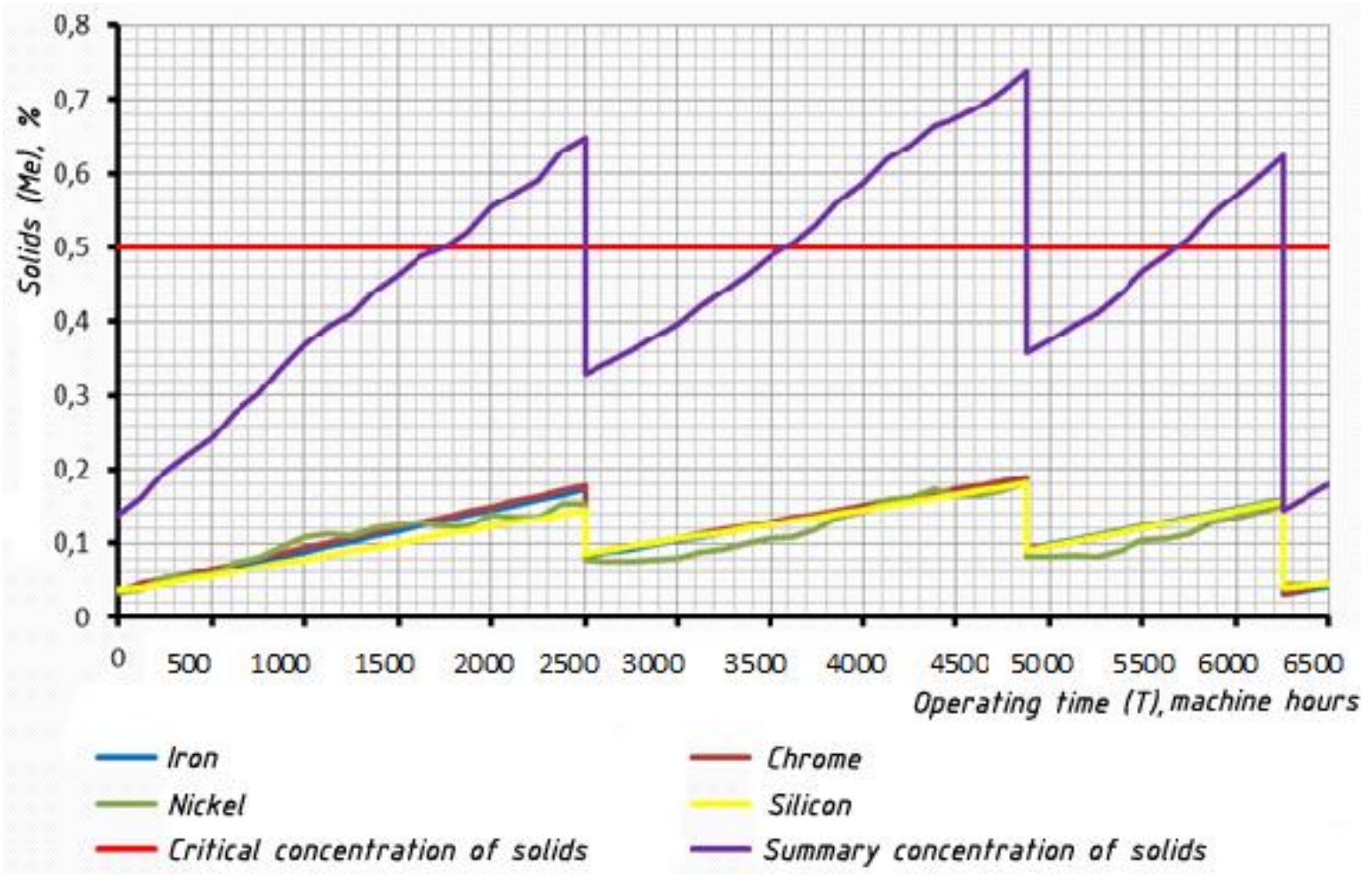

Fig. 1. Graphical Chart of the Content of Solids in Oil versus Operating Time

- $\quad$ products causing wear of the gear parts;

- content of alkali metals (basis of the detergentdispersant and other additives to oils);

silicon - fundamentals of abrasive contaminants in oil.

The table 1 presents maximum permissible content of contaminants in oil.

TABLE 1. Maximum Permissible Content of Contaminants in Oil

\begin{tabular}{|l|c|}
\hline Solids & $\begin{array}{c}\text { Content in Oil of the Gearbox } \\
\text { of the Cutting Part of the } \\
\text { Header SM-130K, \% }\end{array}$ \\
\hline \multicolumn{1}{|c|}{ Iron } & 0.5 \\
\hline Copper & 0.001 \\
\hline Chrome & 0.5 \\
\hline Silicon & 0.5 \\
\hline Nickel & 0.5 \\
\hline
\end{tabular}

Oil samples were taken with the following frequency:

- during regular inspections at every maintenance TS-1;

- before changing oil;

- more often, if there is a suspect on excessive wear.

Fig. 1 shows a set of points characterizing the relationship between the operating time and the change in concentration of various impurities.

As follows from analysis of the figure, the curves have several local extremes, the cause of which during operation is the refilling of fresh oil into gearbox. The results of the experiment showed that mechanical impurities in oil during work of the headers are accumulating almost evenly.

The presence of mechanical impurities in the lubricant oil causes corrosion on surface of the teeth and their abrasive wear out as well as contributes to gas or liquid erosion.

The use of plastic or contaminated lubricant oil, which is accumulator of abrasive particles, stimulates abrasive wear. Later on the worn gear receives gaps in tooth engagement, enhanced noise, vibration, dynamic overload [3]; distorted form of tooth, reduced size of the cross section and strength of tooth. Therefore, to clarify the diagnosis, the next step should be made by clarifying vibro-diagnostic of the operating headers.

Any electromechanical system, including drives of the selective headers, are characterized by three basic conditions $[10,11]$ - satisfactory, acceptable and unacceptable. However, the system of scheduled maintenance valid for operating mines in Kuzbass makes it more important to make a prediction which will give an answer to the main question whether the object of diagnosis will work till the nearest planned maintenance (until the next time of diagnosis) or fail.

To make an effective short-term forecast a number of sources refers to the adaptive short-term prediction [3, 12], which most fully takes into account the diagnostic information contained in the latest measurement. Based on this information, they adjust parameters of the adopted model, i.e. the model adapts to the changed conditions. Prediction using adaptive methods yields good results on relatively small intervals of time (usually $1-2$ intervals ahead), and meet requirements of the scheduled maintenance.

To build a reliable forecast model of degradation for electromechanical equipment it is necessary to select 


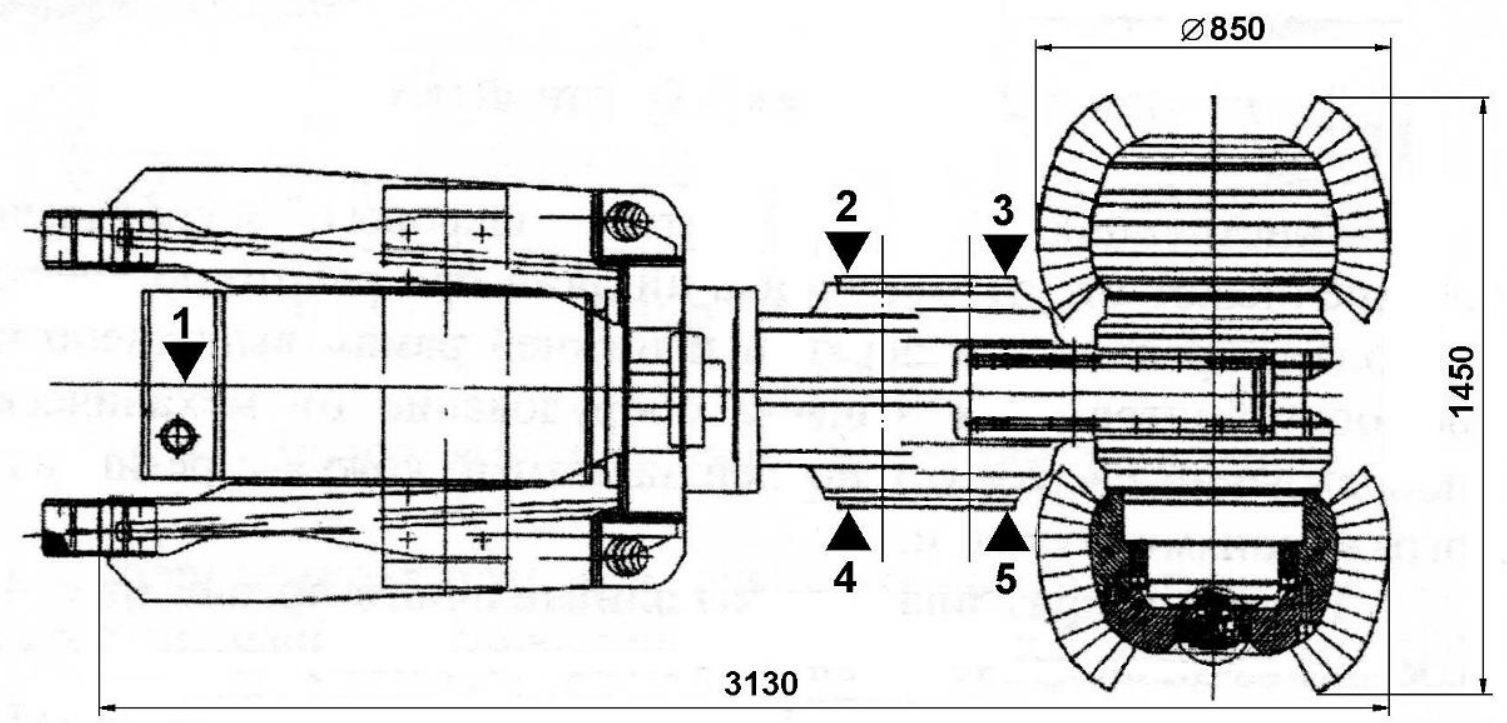

Fig. 2. The Control Points for Vibration Measurements on Cutting Section of the Header SM-130

informative criteria that would allow estimation of the characteristic faults, and in addition, to determine the boundaries of permitted values of the selected criteria. Based on the basic principles of vibration-based diagnosis as informative criterion we should select the index of the peak value of vibration velocity on specific frequencies.

The Fig. 2. Shows the scheme of control points for the vibration measurements.

Let's consider making a forecast based on exponential extrapolation diagnostic results. As previously noted [6], to make prediction for 1 interval of measurement there should be 6 measurements, and to forecast 10 intervals there should be at least 16 measurements.

The Fig. 3a shows the results of control of vibration velocity on bearing assembly of the cutting motor drive of the header SM-130 depending on its operating time after maintenance; and trend line made based on the results of the long-term prediction, as well as the boundaries of transition of the technical condition from satisfactory to acceptable (green), and from acceptable to unacceptable (red). As you can see, 7 thousand hours of operation wears out electric drive almost completely and requires repair of the cutting part.

Comparison of the vibratory activity of the motor supports and gear shows that the source of the elevated vibration is the gearbox.

The Fig. 3b shows the results of diagnostic of cutting gear of the header SM-130, the analysis of the diagnostic shows that the technical condition of the cutting gear by the end of the observation period became unacceptable, and requires repair. Comparison of vibratory activity of the motor supports and gear shows that the source of the elevated vibration is the gearbox.

The analysis of the spectra of the loading of the cutting gear mounting group showed that the most likely defect is a failure of tooth engagement in a planetary gear that causes an elevated vibration of the supporting bearings (Fig. 4).

The subsequent visual inspection and fault detection of the cutting gear showed the correctness of the diagnosis (Fig. 5).

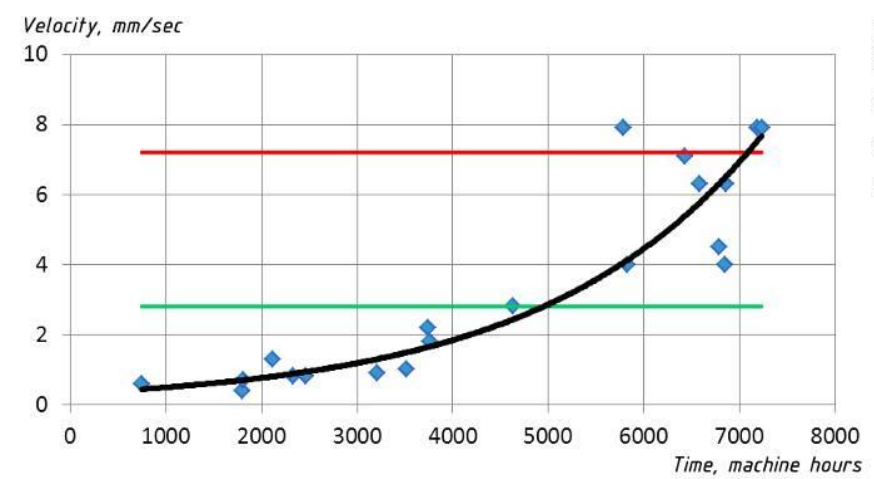

a)

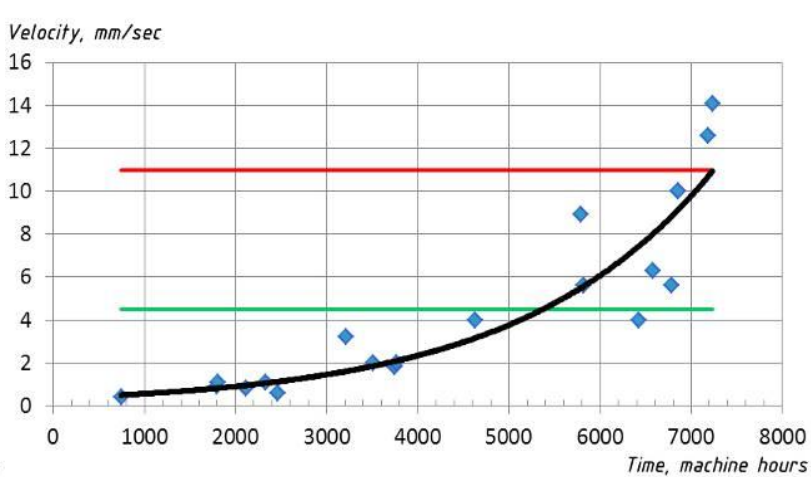

b)

Fig. 3. Results of the Vibration-Based Diagnostics of the Supporting Bearings of Motor (a) and Cutting Gear (b) Header SM130 


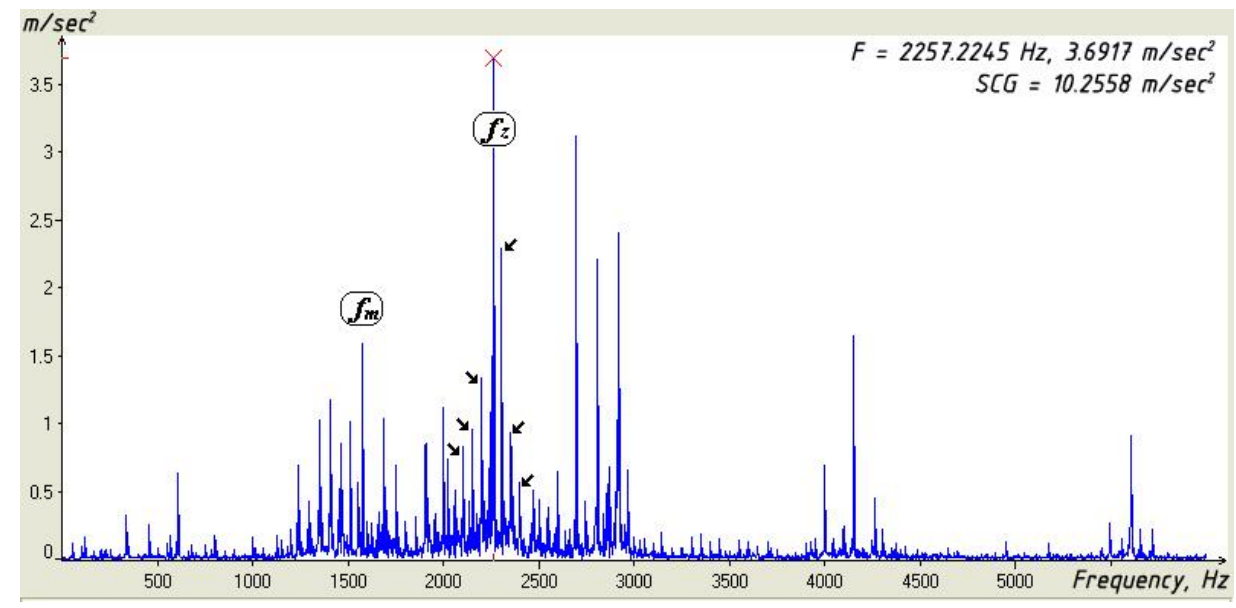

Fig. 4. Spectrum of Vibration Signal from Cutting Gear with the Developed Defect of Contacting Surfaces of Gear Wheels
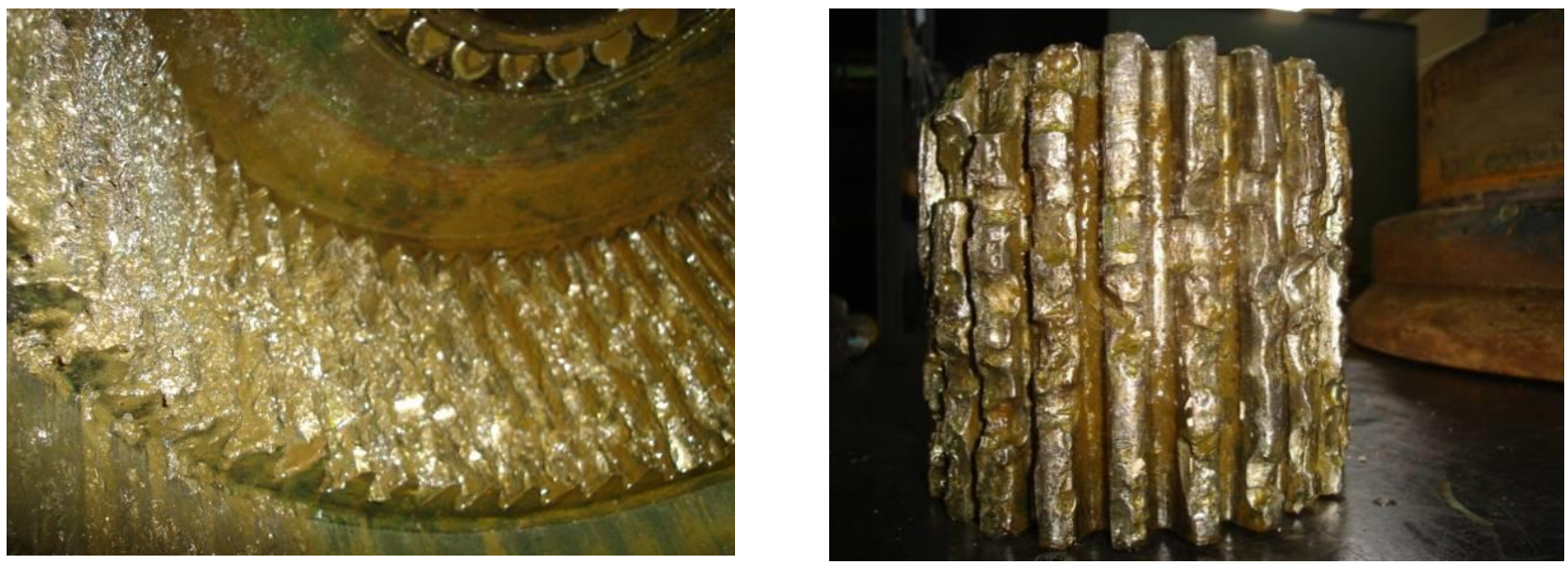

Fig. 5. Defects of the Gear in Harmonic Drive of the Cutting Unit of the Header SM-130

\section{CONCLUSION}

The result of the research shows that the developed forecast model, based on statistical analysis of the results of the lubricant oil and parameters of mechanical vibrations, allows with $95 \%$ confidence probability to predict the point at which a gear of the cutting part of the boom miner enters the breakdown condition, threatening emergency failure of the unit or assembly, and to implement effective maintenance planning, preventing emergency situations.

\section{REFERENCES}

[1] Kovalev V., Gerike B, Khoreshok A., Gerike P. Preventive Maintenance of Mining Equipment Based on Identification of Its Actual Technical State. Taishan Academic Forum: Project on Mine Disaster Prevention and Control. October, 17-20 Qingdao, China. Atlantis Press. Amsterdam, Paris, Beijing. 2014. P. 184-189

[2] Kvaginidze V. S., Kozovoy G.I, Chakvetadze F. A. [and others] Metallokonstruktsiya gornykh mashin. Konstruktsiyi, Ekspluatatsiya. Raschyet [Metal Structures of the Mining Machines. Construction, Operation, Calculation]. Moscow: Gornaya kniga, P.2011. - 392

[3] Gericke B. L., Gericke P. B., Kvaginidze V. S. [and others \} Diagnostika gornykh mashin i oborudovaniya. [Diagnostics of Mining Machines and
Equipment]. Proc. manual./.// M.: SPF 'U Nikitskih Vorot', P.2012. 400

[4] Krakowskiy, Yu. M. Matematicheskiye i programmnye sredstva otsenki technicheskogo sostoyaniya oborudovaniya [Mathematical and Software Tools for Evaluation of the Technical Condition of Equipment]. Novosibirsk: Nauka, 2006. P 228

[5] Klyuev V. V, Fursov A. S., Filinov M. V. Podhody k postroeniyu sistem otsenki ostatochnogo resursa tekhnicheskikh obyektov [Approaches to Construction of Systems of Evaluation of Remaining Life of Technical Objects]. The control. Diagnosis. No. 3. - 2007. P. 18-23

[6] Khoreshok A. A., Mametyev L. E., Sequin A. M. Prokhodcheskiye kombainy so strelovidnym ispolnitelnym organom. Chast 2 . Ekspluatatsiya i diagnostika [Boom-Type Roadheader. Part 2. Operation and Diagnostics: Monograph]. Tomsk: Publishing House of Tomsk Polytechnic University, P 2015. - 281

[7] Pronikov A. S. Nadyezhnost mashin [Reliability of the Machines]. - M.: Mechanical Engineering. 1978. - 390 p.

[8] Gerik, B. L.; Gericke, P. B.; Ederken, P. V. Matematicheskaya model otsenki fakticheskogo sostoyaniya burovogo stanka. Mathematical Model of Assessing the Actual Condition of the Drilling Rig. // Coal, No. 2. - 2010. P. 45-46.

[9] Khoreshok, A. A.; Kudrevatykh, A. V. Metod kompleksnogo diagnostirovaniya reduktorov motor-kolyes karyernykh avtosamosvalov. [Method of Complex Diagnostics of Reduction Gears of Motor-Wheels for Mining Dump Trucks]. Mining industry. - \#5- . 2010, P 60-66. 
[10] GOST ISO 10816-1-97. Vibratsia. Kontrol sostoyaniya mashin po resultatam izmereniy vibratsii na nevraschauschikhtsya chyastyakh. Obschiye trebovaniya [GOST ISO 10816-1-97. Vibration. The Machine Condition Monitor According to the Results of Vibration Measurements on Non-rotating Parts. General requirements]. - Minsk: IPK Publishing house of standards, 1998. P 13 p.

[11] Goldin, A. S. Vibratsiya rotornykh mashin [Vibration of Roters]. - 2-e Updated - M.: Mashinostroenie, 2000. P 344.
[12] Sushko, A. E. Razrabotka matematicheskoy modeli optimalnogo tekhnicheskogo obsluzhivaniya i remonta promyshlennogo oborudovaniya [Development of Mathematical Model of Optimum Maintenance and Repair of Industrial Equipment]. Scientific session MEPhI-2007: Sat. scientific. Tr. 17 Т. М.: МИФИД007. Vol. 2. Р 153154. 